Transactions of the American Fisheries Society 1997, v.126, n.4: p.622-637.

http://afs.allenpress.com/perlserv/?request=get-archive

http://afs.allenpress.com/archive/1548-8659/126/4/pdf/11548-8659-126-4-622.pdf

DOI: $10.1577 / 1548-8659(1997) 126<0622: E A O T I O>2.3 . C O ; 2$

(C) Copyright by the American Fisheries Society 1997

\title{
Experimental Assessment of the Influence of Zooplankton Size and Density on Gizzard Shad Recruitment
}

\author{
Mary T. Bremigan and Roy A. Stein \\ Aquatic Ecology Laboratory, Department of Zoology, The Ohio State University, 1314 Kinnear Road, Columbus, \\ Ohio 43212-1194, USA
}

Abstract.

Available prey influence fish recruitment, especially when size-dependent processes, such as starvation or predation, dictate larval survival. Yet, for zooplanktivorous larval fishes, quantitative assessments of how zooplankton density and quality (i.e., size or taxonomic composition) influence foraging success, growth, and survival are rare. With small-scale experiments, we tested whether high densities of small zooplankton promote recruitment of age-0 gizzard shad Dorosoma cepedianum from the larval ( $<25 \mathrm{~mm}$ total length, TL) to the juvenile ( $\geq 25 \mathrm{~mm} \mathrm{TL}$ ) stage. In our first experiment, in which larval and early juvenile gizzard shad (10-29 mm TL) were exposed to a range of densities of small zooplankton, foraging success varied substantially but generally increased at zooplankton densities over 200/L for larvae less than $20 \mathrm{~mm}$ TL and at densities over 100/L for individuals $20 \mathrm{~mm}$ $\mathrm{TL}$ or longer. In a second experiment, larval gizzard shad (15 mm TL), after 2 weeks in $1-\mathrm{m}^{3}$ enclosures, survived more than $300 \%$ better in enclosures containing small zooplankton (mean $=0.33 \mathrm{~mm}$ ) than in enclosures containing large zooplankton $(0.39 \mathrm{~mm})$, even though growth was similar between treatments. In a third experiment, early juveniles (24 mm TL), after 2 weeks in $1-\mathrm{m}^{3}$ enclosures, grew significantly faster, but survived no better, in high (600 zooplankton/L) than low $(90$ zooplankton/L) densities of small zooplankton. Interactions among zooplankton size, zooplankton density, and gizzard shad size early in life should strongly affect larval gizzard shad success, which in turn should mediate their impact as juveniles on reservoir zooplankton assemblages and ultimately on fish communities.

Development of a synthetic framework that quantifies recruitment mechanisms across fishes remains an elusive goal of fisheries ecology. Both starvation and predation can be critical mechanisms underlying recruitment (Miller et al. 1988; Houde 1994; Leggett and DeBlois 1994). Because both mechanisms can act as size-dependent processes (Forney 1976; Hunter 1981; Rosenberg and Haugen 1982; Rice et al. 1987; Miller et al. 1988; Luecke et al. 1990; Litvak and Leggett 1992; Leggett and DeBlois 1994), much attention has been focused on factors underlying larval size and its influence on larval success. A size-based perspective of fish recruitment has guided both interspecific comparisons that investigate the relationships among phylogeny, life history characteristics (e.g., hatch size, parental care), and recruitment processes (e.g., starvation, predation) and intraspecific comparisons that seek to identify characteristics of individual larvae (e.g., rapid growth) that promote survival (Chambers 1993; Pepin and Miller 1993).

Comparisons generated primarily among species have demonstrated that large larvae are better foragers and are less vulnerable to starvation because they (1) are stronger swimmers (Miller et al. 1988), (2) have better visual acuity and other sensory systems (Blaxter 1986), and (3) have larger gapes (Wong and Ward 1972; Schael et al. 1991; Bremigan and Stein 1994) than their smaller counterparts. Species with a relatively small size at hatch typically are most vulnerable to starvation (Hunter 1981; Miller et al. 1988; Houde 1994); consequently, their recruitment is likely set during the larval stage (Houde 1994) via a strong link between food 
availability and survival. Conversely, species with a relatively large size at hatch are more resistant to starvation. In these species, predation may be the potent ecological force dictating survival and subsequent recruitment (Crowder et al. 1987; Miller et al. 1988; Luecke et al. 1990; Houde 1994).

These interspecific relationships have influenced intraspecific studies of recruitment in marine and freshwater fishes. In marine fishes, which typically hatch at a small size (Houde 1994), intraspecific studies of recruitment have focused on first-feeding larvae, attempting to establish a link between food availability (particularly small zooplankton), growth, and starvation (Rosenberg and Haugen 1982; Frank and Leggett 1986; Cushing 1990; Pedersen et al. 1990). Conversely, most freshwater fishes hatch at a relatively large size (Houde 1994), and intraspecific studies of recruitment in freshwater species have focused on relationships among food availability (particularly large zooplankton), growth, and vulnerability to size-dependent predation (Crowder et al. 1987; Mills and Forney 1988; Mills et al. 1989a, 1989b; Luecke et al. 1990). To date, relatively few intraspecific investigations have fully quantified the relationships among food availability and larval foraging success, growth, and survival (Chambers 1993). Therefore, many questions remain, such as how food quantity and quality combine to produce larval growth rates, and under what conditions do individuals that attain rapid growth rates enjoy higher rates of survival.

Herein, we investigate the role of zooplankton availability in recruitment of gizzard shad Dorosoma cepedianum, a freshwater species with life history characteristics more similar to previously studied marine species. Common in many midwestern and southeastern reservoirs in the United States (Carlander 1969; DeVries and Stein 1990), gizzard shad have high fecundity (200,00-600,000 eggs/female; Bodola 1966) and small size at hatch ( $3.5 \mathrm{~mm}$ total length, TL; Carlander 1969) and provide no parental care. As larvae (age-0 fish $<25 \mathrm{~mm}$ TL), gizzard shad feed exclusively on zooplankton. In contrast to traditionally studied freshwater larvae that typically feed on increasingly larger zooplankton prey as they grow (Siefert 1972; Mathias and Li 1982; Miller et al. 1990; Schael et al. 1991), larval gizzard shad prefer prey smaller than 0.4 $\mathrm{mm}$ throughout larval development (Bremigan and Stein 1994).

As age- 0 gizzard shad reach the juvenile $(\geq 25 \mathrm{~mm}$ TL) stage, their diets broaden to include phytoplankton and detritus in addition to zooplankton (Bodola 1966; Jude 1973; Kissick 1988). In Ohio reservoirs (virtually all of which contain gizzard shad), sport fish recruitment can be positively or negatively influenced by juvenile gizzard shad, depending on their abundance and size (Stein et al. 1995, 1996). Thus, our goal is to predict recruitment of age-0 gizzard shad to an ecological role (i.e., the influential juvenile stage), rather than to a fishery (i.e., the traditional definition of recruitment). Because gizzard shad larvae are small, we hypothesized that differential larval survival rates derive from differences in zooplankton availability and dictate recruitment to the juvenile stage. Accordingly, we focus on direct effects of zooplankton size and density on larval and early juvenile gizzard shad success, building on previous experimental work with zooplankton size (see Bremigan and Stein 1994). Because juvenile gizzard shad consumption of zooplankton can severely reduce the zooplankton available to laterspawned zooplanktivorous larvae of other species (Dettmers and Stein 1992; DeVries and Stein 1992), we also consider the effects of juvenile gizzard shad consumption on zooplankton assemblages.

\section{Methods}

Previously, we documented the relationship between zooplankton size and larval gizzard 
shad foraging (Bremigan and Stein 1994). Here, we describe three subsequent experiments that collectively evaluate the relationships among size and density of zooplankton and foraging, growth, and survival of larval and early juvenile gizzard shad (Figure 1). In experiment 1, we quantify the functional response of larval and early juvenile gizzard shad with small zooplankton as prey. In experiment 2, we explore whether zooplankton size directly affects larval gizzard shad growth and survival. In experiment 3, we evaluate early juvenile gizzard shad growth and survival and explore their effects on zooplankton abundance in high versus low densities of small zooplankton.

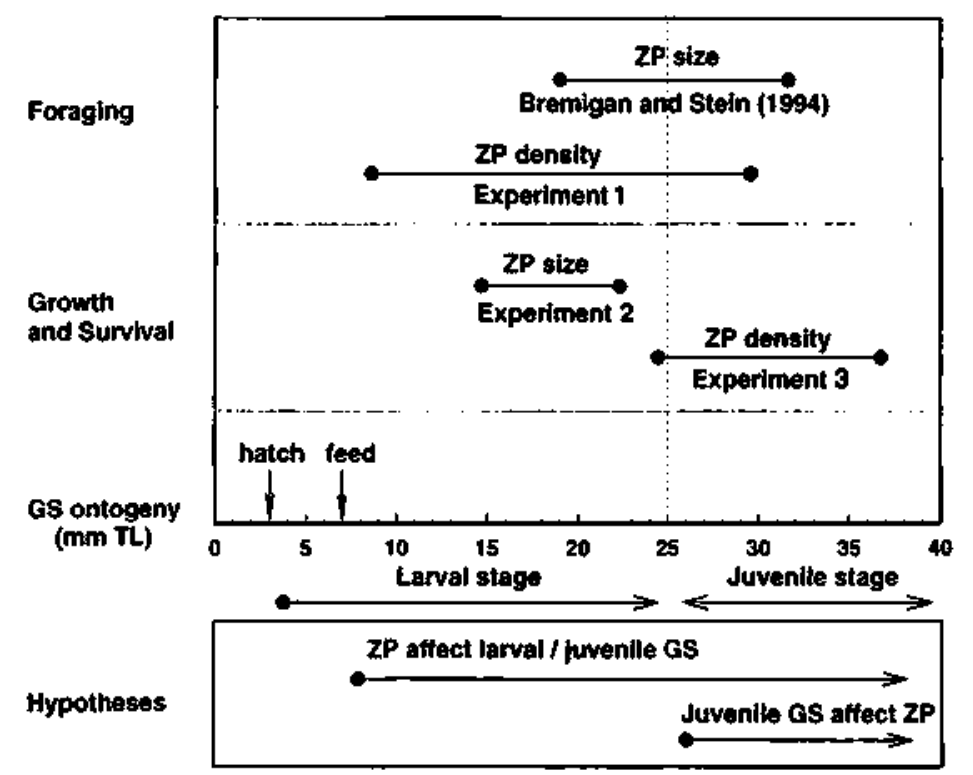

Figure 1.-Framework of experiments designed to evaluate how zooplankton (ZP) size and density influence foraging success, growth, and survival of larval and early juvenile gizzard shad (GS). The vertical dotted line separates the larval and juvenile stages. Size range of gizzard shad involved in each experiment is indicated by the horizontal line. As gizzard shad reach the juvenile stage, we also consider the effects of juvenile gizzard shad consumption on zooplankton density. The relationship between zooplankton size and larval foraging has been previously established (Bremigan and Stein 1994). Here we report three subsequent experiments. Using only preferred zooplankton sizes in experiment 1 , we quantify larval and early juvenile gizzard shad foraging rate as a function of zooplankton density. In experiment 2, we document how zooplankton size affects larval gizzard shad growth and survival. In experiment 3, we document growth and survival of early juvenile gizzard shad, as well as their effects on zooplankton density, in high versus low densities of zooplankton.

Experiment 1. Zooplankton density and larval foraging success.-To study the relationship between food quantity and gizzard shad foraging success, we quantified the functional response of larval $(<25 \mathrm{~mm}$ TL) and early juvenile $(25-30 \mathrm{~mm}$ TL) gizzard shad feeding on small zooplankton. We hypothesized that the number of zooplankton eaten would be a positive function of available zooplankton density and gizzard shad size. We conducted laboratory experiments at constant photoperiod (14 h light : $10 \mathrm{~h}$ dark) and temperature $\left(23^{\circ} \mathrm{C}\right)$ during June 1995. Larvae were collected from Clark Lake, Ohio, as well as from ponds at Hebron (Ohio) State Fish Hatchery. We isolated zooplankton of the size preferred by larval gizzard shad (0.2-0.4 $\mathrm{mm}$ ) by passing hatchery pond zooplankton through a $220-\mu \mathrm{m}$ net. Gizzard shad larvae were fed these small zooplankton ad libitum while maintained in the laboratory.

Experiments were conducted in 10-L circular containers with opaque sides. To ensure that gizzard shad guts were empty at the beginning of an experiment and because gizzard shad 
larvae do not feed at night in the wild (Dettmers and Stein 1992), we isolated four to seven individuals overnight $(\sim 9 \mathrm{~h})$ in each experimental container without zooplankton. The following morning $(0800 \mathrm{~h})$, zooplankton treatment densities were randomly added to each container, thus simulating the early morning feeding conditions of larval gizzard shad in the wild. We established a range of prey availabilities $(<10$ to $>500$ zooplankton/L) inclusive of those documented across Ohio reservoirs (Dettmers and Stein 1996). After 45 min, all gizzard shad were preserved in $95 \%$ ethanol; water from each of the experimental containers was filtered through a $54-\mu \mathrm{m}$ net to retain all remaining zooplankton, which were then preserved in $70 \%$ ethanol. Across 51 experimental containers, we used 245 gizzard shad, ranging 8-29 mm TL. For each container, the number of zooplankton recovered from larval guts was combined with the number remaining in the container to generate available zooplankton density. Details regarding analysis of zooplankton samples and the gut contents of larval fish are described below.

Because larvae cannot be measured without killing them, the size of larvae varied within experimental containers. Therefore, we treat individual larva, not containers, as replicates. Previously, we determined that the number of zooplankton consumed by larval gizzard shad is independent of number of larvae per experimental container (M. T. Bremigan, unpublished data). To assess how zooplankton density and larval size influenced the number of zooplankton eaten, we regressed the number eaten by each larva as a function of those two independent variables and their interaction. To focus on the response of similar-sized larvae to zooplankton density, we grouped larvae into 5-mm size-classes. (The 5-mm size-classes provided sufficient numbers of larvae in each size-class and relatively low variability in the response of larvae to zooplankton density.) Within each size-class, we first viewed the number of larvae that successfully captured zooplankton as a function of zooplankton density. Then, to quantify their functional response to zooplankton density, we performed nonlinear regression analyses, considering only larvae that had consumed at least one zooplankton prey. We did separate analyses for (1) the smallest sizeclass that consumed zooplankton $(\geq 15$ to $<20 \mathrm{~mm}$ TL) and (2) the two larger size-classes combined ( $\geq 20$ to $<25$ and $\geq 25 \mathrm{~mm} \mathrm{TL}$ ), because they responded similarly to zooplankton density. We used the equation

$$
C=(D \cdot M) /(D+K),
$$

where $C$ is the number of zooplankton consumed by each larva, $D$ is the density of zooplankton in that larva's container, $M$ is a fitted parameter corresponding to the maximum number of zooplankton consumed, and $K$ is a fitted parameter corresponding to the density of zooplankton at which consumption reaches $50 \%$ of its maximum.

Experiment 2. Zooplankton size and larval growth and survival.-To test our hypothesis that starvation, due to a lack of appropriately sized prey, drives recruitment of larval gizzard shad, we conducted an enclosure experiment in a 0.4-ha pond $(1.5 \mathrm{~m}$ depth) at the Hebron State Fish Hatchery during May 26-June 7, 1993. The pond was filled in early April 1993 by straining water from nearby Buckeye Lake through a $500-\mu \mathrm{m}$ net; 60 adult gizzard shad that had not yet spawned were then added.

Ten $1-\mathrm{m}^{3}$ enclosures, suspended from $1-\mathrm{m}^{2}$ berths along a wooden walkway, were filled by pumping pond water through a $54-\mu \mathrm{m}$ net that allowed passage of phytoplankton, but not zooplankton. By size-fractionating zooplankton collected from hatchery ponds and a nearby reservoir, we created two distinct treatment assemblages: (1) large zooplankton, which were 
retained by a $365-\mu \mathrm{m}$ net, and (2) small zooplankton, which passed through a $365-\mu \mathrm{m}$ net, but were retained by a $54-\mu \mathrm{m}$ net. Zooplankton treatments were assigned randomly to enclosures $(N$ $=5 /$ treatment). During May 20-23, we iteratively stocked enclosures with zooplankton, then sampled them to establish zooplankton size treatments in which zooplankton density varied, but biomass did not. We then added 40 larval gizzard shad (collected from the pond) to each of five enclosures on May 24 and to each of five more on May 25. During each evening, we collected additional larval gizzard shad (all larvae preserved in 95\% ethanol) to quantify their initial size. Both zooplankton treatments were represented on each stocking night. Four enclosures per treatment were used to quantify larval growth and survival (hereafter, survival enclosures). Larval gizzard shad were sampled from the fifth enclosure from each zooplankton treatment to quantify larval diets through time (hereafter, diet enclosures).

Zooplankton from each enclosure were sampled twice weekly via two hauls of a 2-m tube sampler (internal dimension, $7.3 \mathrm{~cm}$ ). After water volume from the two hauls was recorded, zooplankton retained by a $54-\mu \mathrm{m}$ net were preserved in $70 \%$ ethanol. On each zooplankton sampling date (excluding the first and last days of the experiment), we also collected and preserved up to five larval gizzard shad from both diet enclosures. After 2 weeks, we drained the eight survival enclosures, preserving all larval gizzard shad recovered. We drained the enclosures on two consecutive days, corresponding to the order in which enclosures were stocked with larvae. Pond temperatures ranged from 18 to $24^{\circ} \mathrm{C}$.

To assess the effects of zooplankton size on larval gizzard shad success, we compared the percent survival and mean size of survivors between treatments via $t$-tests, with each enclosure viewed as a replicate. We also compared the size distribution of all survivors from small- versus large-zooplankton enclosures using the Kolmogorov-Smirnov test for equal distributions. To compare the condition of larval gizzard shad between treatments, we regressed the natural log of dry weight of each surviving larva as a function of the natural log of total length and treatment (treatment was used as an indicator variable to distinguish larvae from large- and smallzooplankton enclosures).

We compared zooplankton dynamics between treatments, viewing each survival enclosure as a replicate. For each zooplankton variable (size, density, and biomass), we performed a repeated-measures analysis of variance (ANOVA) followed by analysis of contrasts (von Ende 1993), using the MANOVA procedure in SAS (SAS Institute 1985). For the ANOVA, we report the significance level generated by the multivariate procedure (Pillai's trace), in which observations through time are treated as multiple dependent variables. The analysis of contrasts examined differences in the zooplankton assemblages at successive time intervals, with interval one lying between the first and second sampling dates (days 1 and 3 of the experiment). This technique determines if significant time or time-treatment interactions occurred during each time interval. We adjusted our significance level for this analysis to account for the multiple comparisons being drawn by dividing our desired significance level $(\alpha=0.05)$ by the number of time intervals (4). Therefore, all results of the analysis of contrasts were evaluated at the 0.0125 level of significance. Finally, to assess whether taxonomic changes in zooplankton assemblages in the survival enclosures might be due to larval consumption, we calculated Chesson's alpha (Chesson 1978, 1983) for all larvae from the diet enclosures.

Experiment 3. Zooplankton density and juvenile growth and survival.-To evaluate the hypothesis that high density of small zooplankton promotes growth and survival of larval and juvenile gizzard shad, we conducted an enclosure experiment at the Hebron State Fish Hatchery 
during June 5-19, 1995. Enclosures were constructed as described previously. Zooplankton were collected from hatchery ponds, and the small, preferred sizes that passed through a $220-\mu \mathrm{m}$ net were added to enclosures. High and low densities of small zooplankton (18 enclosures total, 9 enclosures per zooplankton density treatment) were established by adding about $10 \times$ more zooplankton to high-density zooplankton enclosures than to the low-density ones. On the evening of June 5, 1995, we added 12 late-larval gizzard shad ( $24 \mathrm{~mm}$ TL) to each enclosure. In three additional enclosures containing ambient zooplankton, we stocked 12 gizzard shad, then drained these enclosures the following morning to quantify initial size of gizzard shad. We drained the enclosures 4, 8, and $14 \mathrm{~d}$ after fish addition (three enclosures drained per zooplankton treatment per date). Both zooplankton treatment and draining day were randomly assigned among enclosures.

To maintain distinct zooplankton treatments, we stocked additional zooplankton into the high-density enclosures on days 4, 8, and 11. In general, our stocking efforts on these days were slightly less than the initial effort invested in stocking the enclosures. A small amount of zooplankton ( $\sim 0.10$ of the amount added to the high-density zooplankton enclosures) was added to the low-density enclosures on days 8 and 11 to prevent zooplankton elimination. We typically sampled enclosures into which zooplankton had been added on the day before zooplankton addition (days 3, 7, and early on day 11) and then again on the day of zooplankton addition (days 4,8 , and 11) shortly after the addition. We did not add zooplankton if an enclosure was scheduled to be drained on that day; rather, we sampled zooplankton, then drained the enclosure to recover gizzard shad. Pond temperatures ranged from 22 to $25.5^{\circ} \mathrm{C}$.

To compare growth and survival rates of gizzard shad between the two treatments, we performed separate regression analyses for mean wet weight of survivors in each enclosure and the number of survivors in each enclosure as a function of date, treatment (used as an indicator variable), and their interaction. Each enclosure was treated as a replicate. We compared zooplankton density between the two treatments to characterize zooplankton available to the gizzard shad. Because we quantified zooplankton densities before and after zooplankton additions, we could calculate the rate at which zooplankton densities declined. We then could draw inferences regarding gizzard shad consumption rates in each treatment by comparing zooplankton declines between the two treatments.

Laboratory analysis. - To quantify crustacean zooplankton in each of the experiments, we identified (cladocerans to genus; adult copepods as calanoid or cyclopoid; immature copepods as nauplii), counted, and measured (experiment 2 only) crustacean zooplankton using a dissecting microscope with a drawing tube. Each zooplankton sample was placed in a dish divided into 16 equal-sized wedges; all individuals were counted from two opposite wedges of the dish. From these counts, the total number of individuals within each taxon in the entire sample was estimated. If this number was more than 25 , counting of complete wedges continued until at least 50 individuals of that taxon were counted. If the total number of individuals of a taxon, as estimated from the first two wedges, was less than 25 , counting of that taxon stopped because it contributed so little to the entire sample, and the initial estimate of abundance was retained. For experiment 2, at least 20 individuals of each taxon were measured (total body length, excluding spines, helmets, and caudal rami). Zooplankton lengths were converted to biomass by means of taxon-specific length-dry weight regressions (G. G. Mittelbach, Michigan State University, unpublished data). Rotifers (which could be important to much smaller larvae than we used, i.e., $<15 \mathrm{~mm}$ TL) were excluded from our analyses. We did not measure 
zooplankton assemblages from experiments 1 and 3. Previously, we determined that our size fractionation (using only zooplankton that passed through a $220-\mu \mathrm{m}$ mesh) consistently produced zooplankton assemblages with an average size of $\sim 0.25 \mathrm{~mm}$. Therefore, we did not measure zooplankton samples from these two experiments, given their initial narrow size range.

Larval gizzard shad from all three experiments were measured (nearest $0.01 \mathrm{~mm} \mathrm{TL}$ ). Larvae from experiment 2 were dried $\left(24 \mathrm{~h}\right.$ at $80^{\circ} \mathrm{C}$ ) and weighed (nearest $0.1 \mathrm{mg}$ ); in experiment 3, wet weight of individuals (nearest $1 \mathrm{mg}$ ) was recorded. We identified the contents of the entire digestive tract (as described above for zooplankton analysis) from all larvae in experiment 1 , as well as from larvae from the diet enclosures in experiment 2.

\section{Results}

Experiment 1. Zooplankton Density and Larval Foraging Success

Zooplankton density ranged from 4 to 550 zooplankton/L across experimental containers. Assemblages were made up primarily of Bosmina spp. (mean percent composition, numerically, $50 \%$ ), copepod nauplii (22\%), calanoid copepods (15\%), and Ceriodaphnia spp. (8\%). Taxonomic composition of larval gizzard shad diets was similar to previous experiments (Bremigan and Stein 1994). Bosmina spp. were the most common prey eaten by larval gizzard shad (mean percent composition of larval guts, numerically, 72\%); Ceriodaphnia spp. (17\%) were the second most common. Though other zooplankton taxa were moderately abundant in containers, calanoid copepods and copepod nauplii each made up less than $3 \%$ of larval prey items. As larval size increased, percent contribution of Bosmina spp. increased (from $70 \%$ among larvae $<20 \mathrm{~mm}$ TL to $77 \%$ among larvae $\geq 25 \mathrm{~mm} \mathrm{TL}$ ), whereas the contribution of copepod nauplii declined (from $11 \%$ among larvae $<20 \mathrm{~mm}$ TL to $1 \%$ among larvae $\geq 25 \mathrm{~mm}$ TL). Zooplankton were not depleted by gizzard shad consumption. For $92 \%$ of the containers, less than $30 \%$ of the zooplankton available at the start of the feeding trial were consumed by gizzard shad during the 45-min trial.

Numbers of zooplankton eaten increased as larval total length and zooplankton density increased $\left(r^{2}=0.58 ; F=109.96 ; \mathrm{df}=3,241 ; P=0.0001\right)$; we also noted a positive interaction between larval length and zooplankton density ( $t$-test for coefficient $=0, P=0.0001$ ). Considering larvae grouped into 5-mm size-classes, percent of feeding larvae increased with larval length and zooplankton density (Figure 2). No gizzard shad less than $15 \mathrm{~mm}$ TL fed ( $N=$ 21 larvae). For larvae 15-19 mm TL, the proportion of larvae that consumed any zooplankton increased from about $30 \%$ at zooplankton densities less than $100 / \mathrm{L}$ to about $70 \%$ at densities above 300/L. Proportion of larvae that consumed any zooplankton was higher among larvae longer than $20 \mathrm{~mm}$ TL (always exceeding 75\%) and increased at zooplankton densities higher than 200/L (Figure 2).

Quantification of the functional response of each of the larval size-classes to zooplankton density revealed marked variability in foraging rates among individual larva (Figure 3). For the 15-19-mm size-class, the $95 \%$ confidence intervals (CI) for both $M$ and $K$ (the fitted model parameters corresponding to maximum number of zooplankton consumed and density at which consumption reaches $50 \%$ of its maximum, respectively) included 0 , indicating that the model did not adequately represent the data. For the combined larger size-classes, number of zooplankton eaten increased with zooplankton density, with the steepest increase between zooplankton densities of $0-100 / \mathrm{L}$. Although the $95 \% \mathrm{CI}$ for $M$ and $K$ did not include 0 , these intervals were quite broad $(M=169.73,95 \% \mathrm{CI}=102.9-236.5 ; K=274.0,95 \% \mathrm{CI}=60.0-$ 488.0 ), reflecting the variability in number of zooplankton consumed among larvae exposed to 
similar zooplankton densities (Figure 3). Overall, number of zooplankton consumed was much higher for gizzard shad $20 \mathrm{~mm}$ TL and larger than for larvae 15-19 mm TL. For example, mean numbers of zooplankton in guts of larvae less than $20 \mathrm{~mm}$ TL and $20 \mathrm{~mm}$ TL and longer, respectively, were 2.2 and 22.9 at zooplankton densities ranging $0-100$ zooplankton/L and 5.1 and 78.8 at densities higher than $200 / \mathrm{L}$.

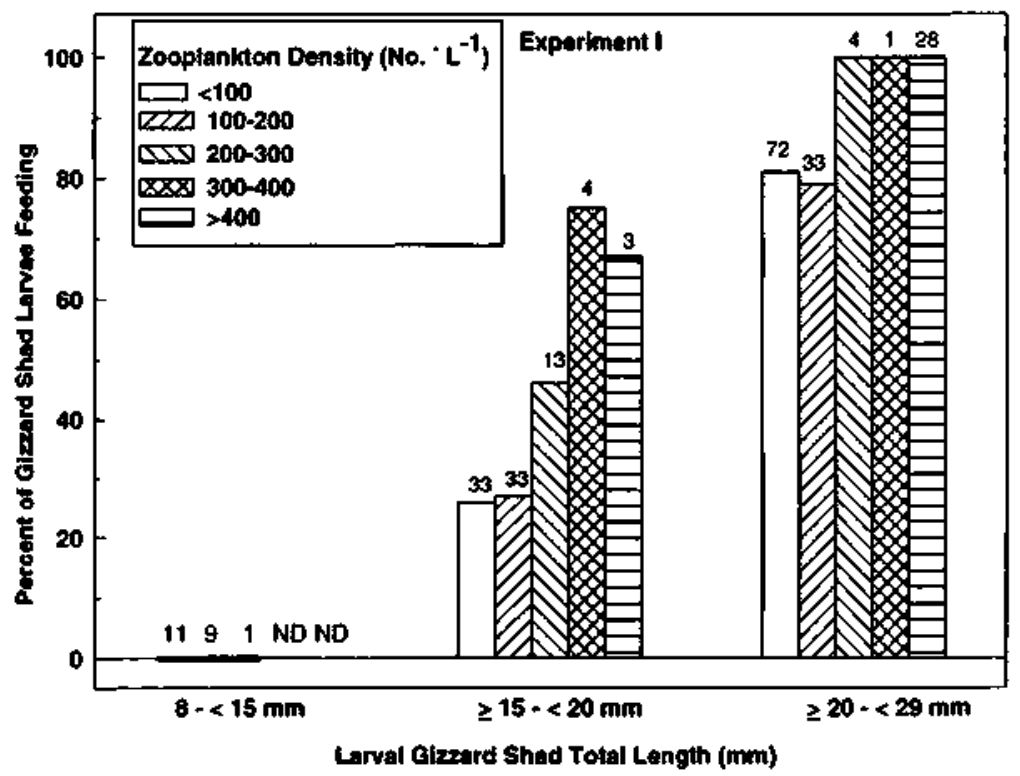

Figure 2.-Percent of larval gizzard shad that successfully captured at least one zooplankton prey in 10-L containers in laboratory experiment 1 , as a function of larval gizzard shad total length $(\mathrm{mm})$ and zooplankton density (number/L). Larvae from the two largest size-classes ( $\geq 20$ to $<25 \mathrm{~mm} \mathrm{TL}$ and $\geq 25 \mathrm{~mm}$ TL) were combined because they responded similarly to zooplankton density. Number of larvae in each comparison is given above each bar. We exposed more larvae to the range of $0-200$ zooplankton/L because most Ohio reservoirs fall within this range (Bremigan, unpublished data): ND signifies no data for that combination.

\section{Experiment 2. Zooplankton Size and Larval Growth and Survival}

Length of larval gizzard shad added to enclosures did not differ between two consecutive stocking nights $(t$-test: $\mathrm{df}=48,52 ; P=0.65)$; therefore, larvae from both nights were pooled. Initial size of larval gizzard shad was $15.0 \mathrm{~mm} \mathrm{TL} \pm 0.29( \pm \mathrm{SE})$. Zooplankton size influenced larval gizzard shad survival. After 2 weeks, mean percent survival was $300 \%$ greater in smallzooplankton enclosures than in large-zooplankton enclosures (mean survival $=33 \%$ and $11 \%$, respectively; $t$-test on arcsin-square-root-transformed percentages: $\mathrm{df}=3,3 ; P=0.003$ ). Mean total length of surviving larvae did not differ between treatments (overall mean TL $\pm \mathrm{SE}=21.7 \pm$ $0.29 \mathrm{~mm}$; $t$-test for difference between treatment means: $\mathrm{df}=3,3 ; P=0.46$ ), nor did their length distributions (Kolmogorov-Smirnov test, $P=0.10$ ), nor their variance ( $F$-test for equal variance: $F=1.37 ; \mathrm{df}=51,16 ; P=0.50)$. Larval condition did not vary between treatments. Overall, the model of $\log _{e}$ larval dry weight as a function of $\log _{e}$ total length and treatment explained a significant amount of variability in larval weight $\left(N=68 ; r^{2}=0.95 ; F=444.7 ; \mathrm{df}=3,64 ; P=\right.$ 0.0001); however, the interaction between total length and zooplankton treatment did not contribute to the model ( $t$-test for coefficient $=0, P=0.135$ ), demonstrating that the slope of larval weight versus length did not vary between treatments.

Initially, both size and density of crustacean zooplankton differed between treatments. A higher density was stocked into small-zooplankton enclosures than into large-zooplankton 
enclosures, such that zooplankton biomass did not differ between treatments (Table 1). In both treatments, zooplankton $0.2-0.4 \mathrm{~mm}$ were most abundant numerically $(66 \%$ and $96 \%$ in the large- and small-zooplankton enclosures, respectively); as a result, the difference in overall mean zooplankton size between treatments, although significant, was small (Table 1). Even so, zooplankton biomass available for consumption by larval gizzard shad varied substantially between treatments. For 15-mm larvae, with a gape of about $0.4 \mathrm{~mm}, 84 \%$ of the zooplankton biomass was available on day 1 in the small-zooplankton treatment, but only $20 \%$ was available in the large-zooplankton treatment. Size differences were reflected in the taxonomic composition of these assemblages. Bosmina spp. were most abundant, numerically, in both treatments, making up a larger proportion of the assemblages in small- than large-zooplankton enclosures, followed by copepod nauplii (Table 1). Daphnia spp. was moderately abundant in the largezooplankton treatment but was nearly absent in small-zooplankton enclosures. Relative to biomass, Daphnia spp. dominated the large-zooplankton treatment, followed by Bosmina spp. and cyclopoid copepods, whereas Bosmina spp. made up nearly $90 \%$ of the zooplankton biomass in the small-zooplankton treatment, followed by Daphnia spp. and cyclopoid copepods. Therefore, these two treatments differed primarily in the relative biomass of Bosmina spp. versus Daphnia spp. (Table 1).

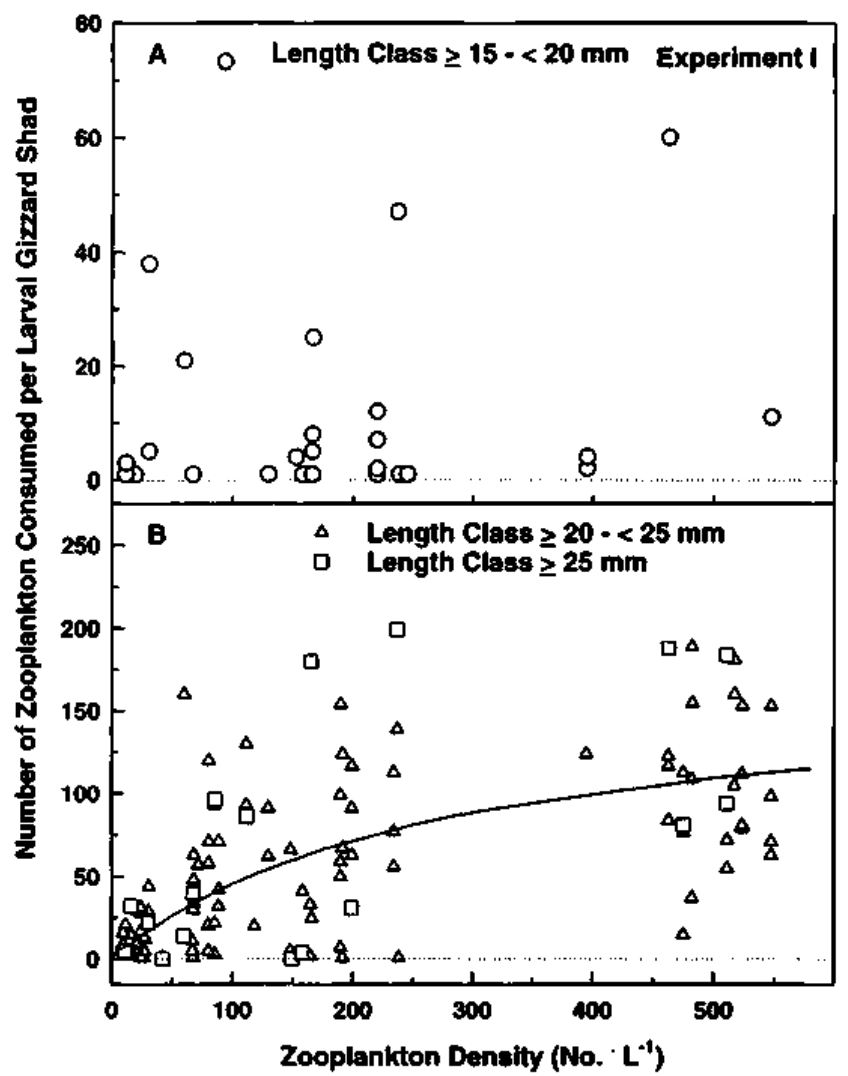

Figure 3.-Number of zooplankton in larval gizzard shad guts as a function of available zooplankton density for (A) small larvae ( $\geq 15$ to $<20 \mathrm{~mm}$ TL) and (B) large larvae ( $\geq 20 \mathrm{~mm}$ TL) in 10-L containers in laboratory experiment 1 . Only larvae that had consumed at least one zooplankter are represented. For large larvae, functional response model predictions are indicated by the solid line. Model predictions are not shown for small larvae because the confidence intervals for the parameter estimates included 0 .

Upon addition of larval gizzard shad, crustacean zooplankton assemblages rapidly 
changed. The most striking responses were in small-zooplankton enclosures immediately after stocking (Figure 4). Mean zooplankton size changed during the experiment (Table 2: A, date effect), declining significantly during the first three time intervals (Table 2: $\mathrm{B}$, date effect). During the first time interval, zooplankton size in the small-zooplankton enclosures declined most abruptly (Table 2: B, date $\times$ treatment effect). Zooplankton densities changed significantly during the experiment (Table 2: A, date effect); dynamics differed marginally in small- versus large-zooplankton enclosures (Table 2: A, date $\times$ treatment effect). Zooplankton density declined in both treatments during the first and last time intervals (Table 2: B, date effect). Changes in zooplankton biomass over time (Table 2: A, date effect) were similar in both treatments. (Table 2: A, date $\times$ treatment effect). Zooplankton biomass declined during the first time interval (Table 2: B, date effect). In summary, the most marked changes in zooplankton density and biomass occurred during the first time interval. Changes in zooplankton size, quite evident during the first time interval in the small-zooplankton enclosures, were somewhat more gradual in the largezooplankton enclosures.

Crustacean zooplankton dynamics can be explained by considering (1) compositional changes in assemblages through time and (2) diets of larval gizzard shad. By day 3, density of Bosmina spp. had declined dramatically in both treatments, accounting for the marked declines in zooplankton density and biomass, especially within small-zooplankton enclosures (Figure 5). Densities of Bosmina spp. continued to decline through the experiment. In the large-zooplankton enclosures, although biomass of Daphnia spp. also declined, it exceeded biomass of Bosmina spp. during the experiment. Changes in zooplankton size through time were due, at least in part, to changes in relative abundance across species. For example, an increase in percent composition of copepod nauplii (which generally are $<0.20 \mathrm{~mm}$ ) in both treatments contributed to declining mean size. To determine if changes in mean size within the dominant zooplankton taxa contributed to the changes in overall mean size, we performed separate repeated-measures ANOVA for Bosmina spp. and Daphnia spp. Neither analysis detected changes in the size of these taxa throughout the duration of the experiment.

Larval gizzard shad consumption probably contributed to zooplankton dynamics. On days 3, 7, and 10 in both the small- and large-zooplankton diet enclosures, those larval gizzard shad with zooplankton in their guts ranged from 20 to $80 \%$; obvious patterns between treatments did not exist. Larval gizzard shad consumed Bosmina spp. in highest abundance $(58 \%$ of all prey), followed by Ceriodaphnia spp., cyclopoid copepods, and Daphnia spp. Accordingly, Bosmina spp. and Ceriodaphnia spp. were consistently selected by larval gizzard shad in both treatments (mean Chesson's alpha for larvae from the large- and small-zooplankton diet enclosures, $N=8$ fish per enclosure, respectively: Bosmina, 0.47 and 0.28; Ceriodaphnia, 0.34 and 0.42 ; neutral selectivity, 0.17 ).

\section{Experiment 3. Zooplankton Density and Juvenile Growth and Survival}

Gizzard shad grew faster in high-density zooplankton (HZP) enclosures (Figure 6A), leading to larger juveniles (mean final $\mathrm{TL} \pm \mathrm{SE}=35.5 \pm 0.63 \mathrm{~mm}$ ) than in low-density zooplankton (LZP) enclosures (mean final TL $\pm \mathrm{SE}=30.07 \pm 0.17 \mathrm{~mm}$ ). Mean juvenile wet weight varied with date, treatment, and their interaction $\left(N=20 ; r^{2}=0.84 ; F=27.18 ; \mathrm{df}=3,16\right.$; $P=0.0001$; $t$-test for interaction coefficient $=0, P=0.013)$, revealing that juvenile gizzard shad in HZP enclosures grew faster than those in LZP enclosures. Number of larvae surviving ranged from 87 to $93 \%$ and did not differ between treatments or through time $\left(F=1.33 ; r^{2}=0.22\right.$, $\mathrm{df}=$ $3,14 ; P=0.30)$. 
Table 1.-Mean zooplankton (ZP) variables (SE in parentheses) for small- and large-zooplankton enclosures within a pond at Hebron (Ohio) State Fish Hatchery on day 1 (May 26, 1993) of experiment 2. Size (mm), density (number/ $\mathrm{L}$ ), and biomass (mg dry weight/L), combining all zooplankton taxa, for the small- and large-zooplankton enclosures were compared by individual $t$-tests: $P$-values for each test are provided. In addition, the four most abundant taxa were analyzed individually for size $(\mathrm{mm})$, density (percent composition by number), and biomass (percent composition by dry weight). For the individual taxa, $t$-tests comparing density and biomass were performed with arcsine-square-root transformations of the percent composition data.

\begin{tabular}{|c|c|c|c|c|c|c|c|}
\hline \multirow[b]{3}{*}{ Treatment or stacistic } & \multirow[b]{3}{*}{$N$} & \multirow{2}{*}{\multicolumn{3}{|c|}{ All tuxu }} & \multicolumn{3}{|c|}{ 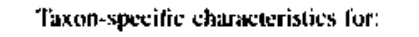 } \\
\hline & & & & & \multicolumn{3}{|c|}{ Bosumina spp. } \\
\hline & & Siak & Density & Biomass & size & Ditnsily & Biamas: \\
\hline Smatl ZP & 4 & $\begin{array}{c}0.33 \\
10.060\end{array}$ & $\begin{array}{l}1.145 \\
(101)\end{array}$ & $\begin{array}{c}1.76 \\
(0,13)\end{array}$ & $\begin{array}{c}0.34 \\
10.011\end{array}$ & $\begin{array}{c}90 \% \\
(0,43)\end{array}$ & $\begin{array}{c}\sin \\
0,00)\end{array}$ \\
\hline Large ZP & 4 & $\begin{array}{c}0.39 \\
(0.01)\end{array}$ & $\begin{array}{l}518 \\
(87)\end{array}$ & $\begin{array}{c}1.10 \\
(0.27)\end{array}$ & $\begin{array}{c}0.3,3 \\
(0.01)\end{array}$ & $\begin{array}{c}524 \\
(0.05)\end{array}$ & $\begin{array}{c}337 \\
\text { (1). } 104\end{array}$ \\
\hline P. valut & & $\$ 1.02$ & d).010.7 & $0+43$ & 0.86 & Monk & 0,60007 \\
\hline
\end{tabular}

Table 1.-Extended.

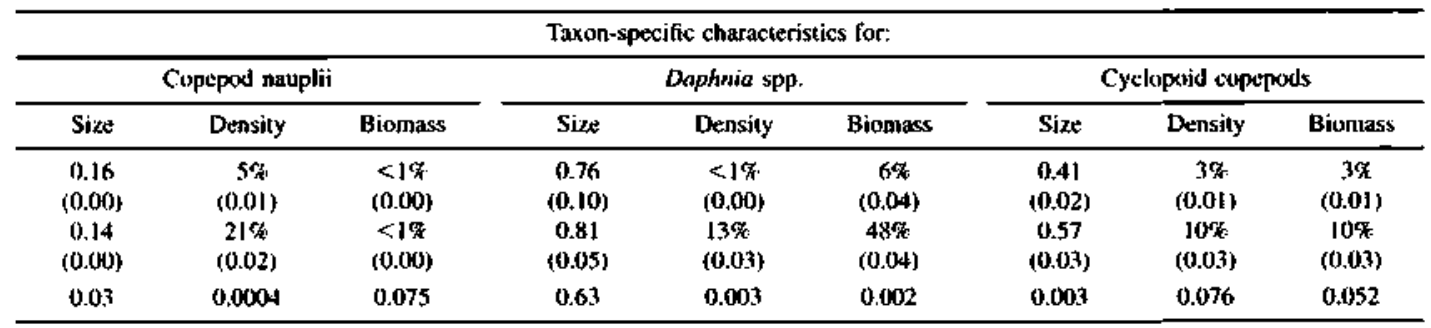

Zooplankton densities in HZP enclosures, on average, exceeded densities in LZP enclosures by more than six times (grand means $\pm \mathrm{SE}$ : HZP, $591 \pm 168$ zooplankton/L, LZP, 86 \pm 23 ; $t$-test, $t=2.97, P=0.02$; Figure $6 \mathrm{~B}$ ). Zooplankton assemblages in both treatments were made up of copepod nauplii (average percent composition, numerically: HZP, 54\%; LZP, 46\%), Bosmina spp. (HZP, 22\%; LZP, 32\%), and calanoid copepods (HZP, 16\%; LZP, 9\%).

Mean rate of daily zooplankton decline in HZP enclosures was $215 \pm 97$ zooplankton/L, which far exceeded mean daily decline in LZP enclosures of $9 \pm 23$ zooplankton/L, indicating that gizzard shad consumed zooplankton at much greater rates in HZP than in LZP enclosures. Although mean zooplankton density differed between treatments by a factor of 6 , the magnitude of zooplankton declines differed between treatments by a factor of 24 .

\section{Discussion}

In our experiments, we detected positive relationships among food availability, foraging success, and survival for small gizzard shad larvae ( $<20 \mathrm{~mm}$ TL), and among food availability, foraging success, and growth for large larvae ( $\geq 20 \mathrm{~mm}$ TL) and early juveniles. Below, we consider how the relationships between zooplankton availability and age-0 gizzard shad success change with the ontogeny of gizzard shad and their implications for gizzard shad recruitment across systems.

\section{Zooplankton, Gizzard Shad Ontogeny, and Recruitment}

For small larvae exposed to increasing zooplankton density in experiment 1, foraging success increased; therefore, their susceptibility to starvation mortality should decline. However, because their foraging success was quite variable, even at high zooplankton densities, relatively few larvae should survive. Accordingly, in experiment 2, lack of appropriately sized prey 
increased starvation mortality of larvae, yet did not reduce growth. We believe that the effects of zooplankton size on mortality occurred early in the experiment. With a spotlight at night, we observed larvae in experimental enclosures, noting a marked decline between days 1 and 3, but little change during days 3-13. If most larval mortality occurred within the first $3 \mathrm{~d}$, then differences in growth rate among larvae may have had insufficient time for expression, suggesting that growth differences, as a direct response to zooplankton size, do not contribute directly to survival processes. However, if a minimum growth rate is required for survival, then more larvae may have foraged and achieved that growth rate in small-zooplankton enclosures. In this scenario, larval growth rates could have contributed to the survival response, even though we detected no difference in size among survivors.

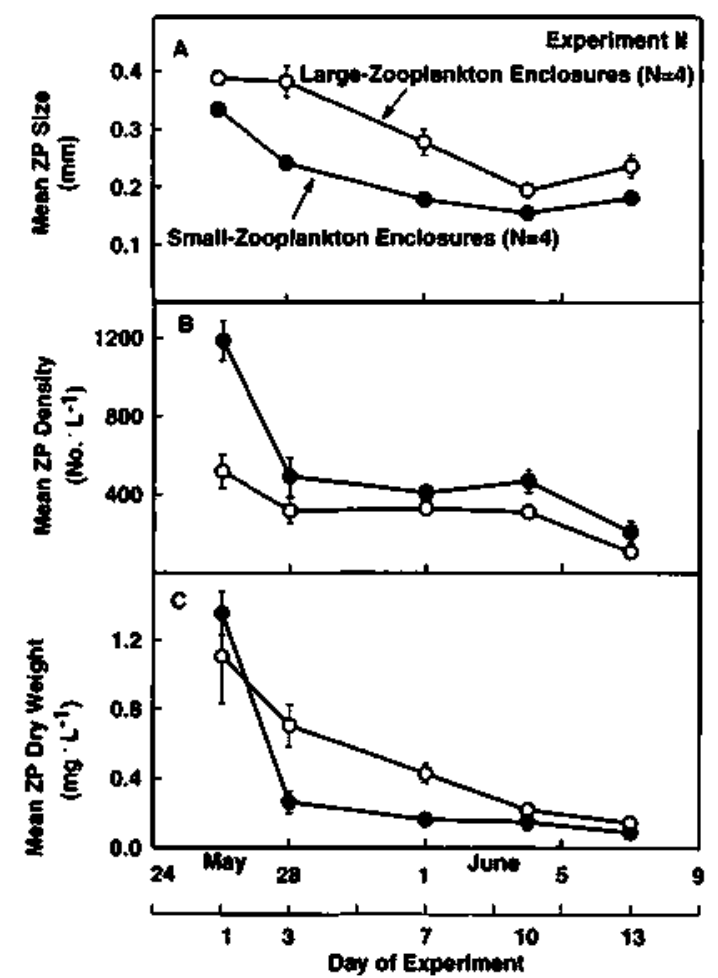

Figure 4.-Comparison of zooplankton dynamics in the large- and small-zooplankton (ZP) enclosures ( $N=$ four 1$\mathrm{m}^{3}$ enclosures per treatment) of experiment 2 (May 26-June 7, 1993) within a pond at Hebron State Fish Hatchery. Panels show mean \pm SE changes in (A) size, (B) density, and (C) total biomass of crustacean zooplankton.

The three-fold higher larval survival rate in the small-zooplankton enclosures was quite impressive, considering that even small differences in larval survival can produce very large differences in the number of survivors (Houde 1987). Further, the initial size of larvae $(15 \mathrm{~mm}$ TL) was large relative to their size at first feeding $(6 \mathrm{~mm} \mathrm{TL})$. Because larval gizzard shad 6-15 $\mathrm{mm}$ TL should be more severely gape-limited than their larger counterparts, our measure of the positive effect of small zooplankton on larval success was conservative.

Because zooplankton taxonomic differences underlie size differences, we can not completely distinguish between effects of zooplankton size and taxa. In other words, small taxa (i.e., copepod nauplii and Bosmina) and large taxa (i.e., Daphnia) may possess differences in addition to size (i.e., antipredator behavior or nutritional quality) that differentially affect larval gizzard shad success. Overall, the difference in mean size of zooplankton between treatments 
( 0.33 versus $0.39 \mathrm{~mm}$ ) generated quite different zooplankton assemblages available to larval gizzard shad both in terms of size and taxa; yet, it was small relative to real-world differences (mean zooplankton size ranged 0.4-1.3 mm in New York lakes; Mills et al. 1987). Therefore, freshwater systems should differ dramatically with regard to their recruitment environment for larval gizzard shad, with many lakes containing very low densities of the small zooplankton taxa that larval gizzard shad require. For example, in Crystal Lake, Connecticut, in which large taxa dominated (Daphnia, Diaptomus, and Mesocyclops) and average size was about $0.8 \mathrm{~mm}$, only $1 \%$, by number, of the zooplankton were less than $0.4 \mathrm{~mm}$ (Brooks and Dodson 1965). Therefore, in systems with large zooplankton, we believe that survival of larval gizzard shad, and hence their recruitment, should be compromised quite dramatically, unless perhaps, zooplankton densities are extremely high. For example, if a system with a relatively large mean zooplankton size had an extremely high density of zooplankton, then encounter rates of larval gizzard shad with small zooplankton might be high enough to allow larval gizzard shad to successfully forage. However, the size efficiency hypothesis (Brooks and Dodson 1965) predicts that high densities of large and small zooplankton will not coexist. Accordingly, we predict that most systems in which large zooplankton dominate will support low densities of the small zooplankton that promote larval gizzard shad success.

Table 2.-Multivariate repeated-measures analysis of variance of zooplankton dynamics in experiment 2. Separate analyses were performed for zooplankton size, density, and biomass. The date effect reflects changes in the zooplankton assemblages over the 2 weeks of the experiment. A significant interaction term reflects a lack of parallelism of zooplankton dynamics between treatments. As a part of each analysis we performed an analysis of contrasts, which tests for date and date $\times$ treatment effects during each time interval. Because we sampled on five dates over the duration of the experiment, there were four intervals, each representing a 3-4-d period. To control for the multiple comparisons being drawn (i.e., four time intervals within each analysis), we divided 0.05 by 4 to achieve a confidence level 0.0125 for the analysis of contrasts.

\begin{tabular}{|c|c|c|c|c|c|c|c|}
\hline \multirow[b]{2}{*}{ Cumparisons } & \multicolumn{3}{|c|}{ A: Statistics lor all data } & \multicolumn{4}{|c|}{ B: P-values lot specific lime inletrals } \\
\hline & Pilltit's Irace & $F$-stutistic & $P$-value & Interval I & Interval 2 & Intefeval 3 & Interval 4 \\
\hline \multicolumn{8}{|l|}{ Zooplanklon size } \\
\hline Dille & 1.00 & 869.9 & $0.00 !$ & 0.0001 & 0001 & 0.008 & 0.083 \\
\hline Dille $X$ trealment & 0.87 & 3.2 & 0.25 & 0.005 & 0.512 & 0.057 & 0,712 \\
\hline \multicolumn{8}{|l|}{ Zixiplanklem densily } \\
\hline Date & o.9y & 73.9 & 0,013 & 0.002 & $0.6,74$ & 0.729 & 0.0002 \\
\hline Date $X$ ineatment & 0.95 & 10.2 & 0.092 & 0.022 & 0.679 & 0.329 & 0.119 \\
\hline \multicolumn{8}{|l|}{ Zoxplanktum biomsass } \\
\hline Datc & 0.48 & 210 & 0.045 & 0.005 & 0.0 .72 & 0.050 & 0.218 \\
\hline Date $\times$ treatumtont & 0.85 & 2.8 & 0.277 & 0.242 & 0.456 & 0.070 & 0.487 \\
\hline
\end{tabular}

For large gizzard shad larvae, which consumed zooplankton even at low zooplankton densities in experiment 1 and which, therefore, should be less susceptible to starvation, high zooplankton density in experiment 3 enhanced both foraging success and growth but did not improve survival. If large larvae and juvenile gizzard shad were equally vulnerable to starvation as larvae less than $20 \mathrm{~mm}$ TL, then we would expect high mortality in experiment 3 because zooplankton densities in the low zooplankton enclosures (always $<200$ zooplankton/L) were lower than initial densities of small zooplankton in experiment $2(\sim 300$ zooplankton $<0.4 \mathrm{~mm} / \mathrm{L}$ in the large-zooplankton treatment). High gizzard shad survival in experiment 3 can be attributed to two factors: (1) increased resistance to starvation and (2) alternate prey resources. Omnivorous as juveniles, these gizzard shad could consume phytoplankton as well as algae attached to enclosure walls. Given abundant algae and detritus in reservoirs, direct mortality of juvenile gizzard shad due to low densities of zooplankton should be low; even so, juvenile gizzard shad 
growth should correlate positively with zooplankton abundance because zooplankton represent a preferred, energy-rich resource compared with detritus (Bowen et al. 1995; Yako et al. 1996).

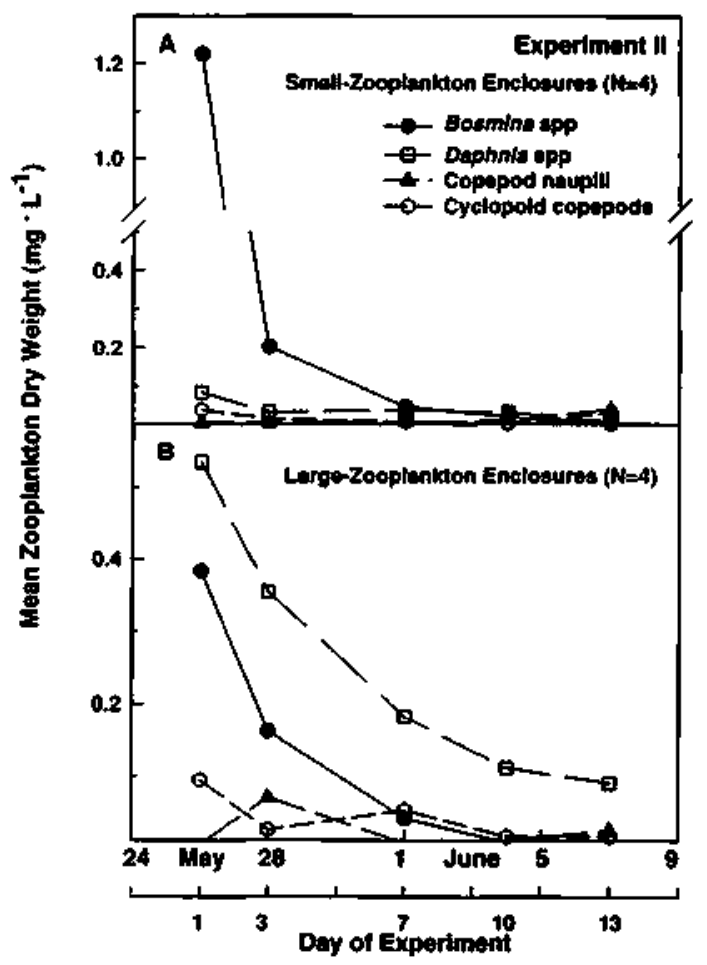

Figure 5.-Changes through time in biomass (mg dry weight/L) of crustacean zooplankton in (A) small-zooplankton and (B) large-zooplankton enclosures within a pond at Hebron State Fish Hatchery during experiment 2 (May 26-June 7, 1993).

In both experiments 2 and 3 , consumption by age- 0 gizzard shad appeared to affect zooplankton assemblages. In experiment 2, Bosmina spp., the taxa most prevalent in guts of larval gizzard shad from the diet enclosures, declined substantially following larval gizzard shad addition. Further, based on experiment 1, we would expect gizzard shad consumption in experiment 3 to be higher in the high-zooplankton density enclosures than in the lowzooplankton density ones. However, declines in zooplankton density also could be due, at least in part, to lack of appropriate algal resources for zooplankton in the enclosures. Without fishless enclosures, we can not distinguish the effects of gizzard shad consumption and algal resources on zooplankton dynamics. However, both DeVries and Stein (1992) and Dettmers and Stein (1996), using fishless enclosures in shallow reservoirs, demonstrated that zooplankton persist in fishless enclosures, but zooplankton decline in enclosures containing age-0 gizzard shad. Thus, we believe that gizzard shad consumption contributed strongly to zooplankton dynamics in our experimental enclosures.

Similar to marine species that hatch at a small size, gizzard shad, a freshwater species with high fecundity, small hatch size, and no parental care, appears quite vulnerable to zooplankton-mediated starvation as small larvae. Our results support the hypothesis that the relative importance of starvation and predation in driving recruitment varies somewhat predictably among species according to their life history strategies, with starvation most important in species with a small hatch size (Miller et al. 1988; Houde 1994). 


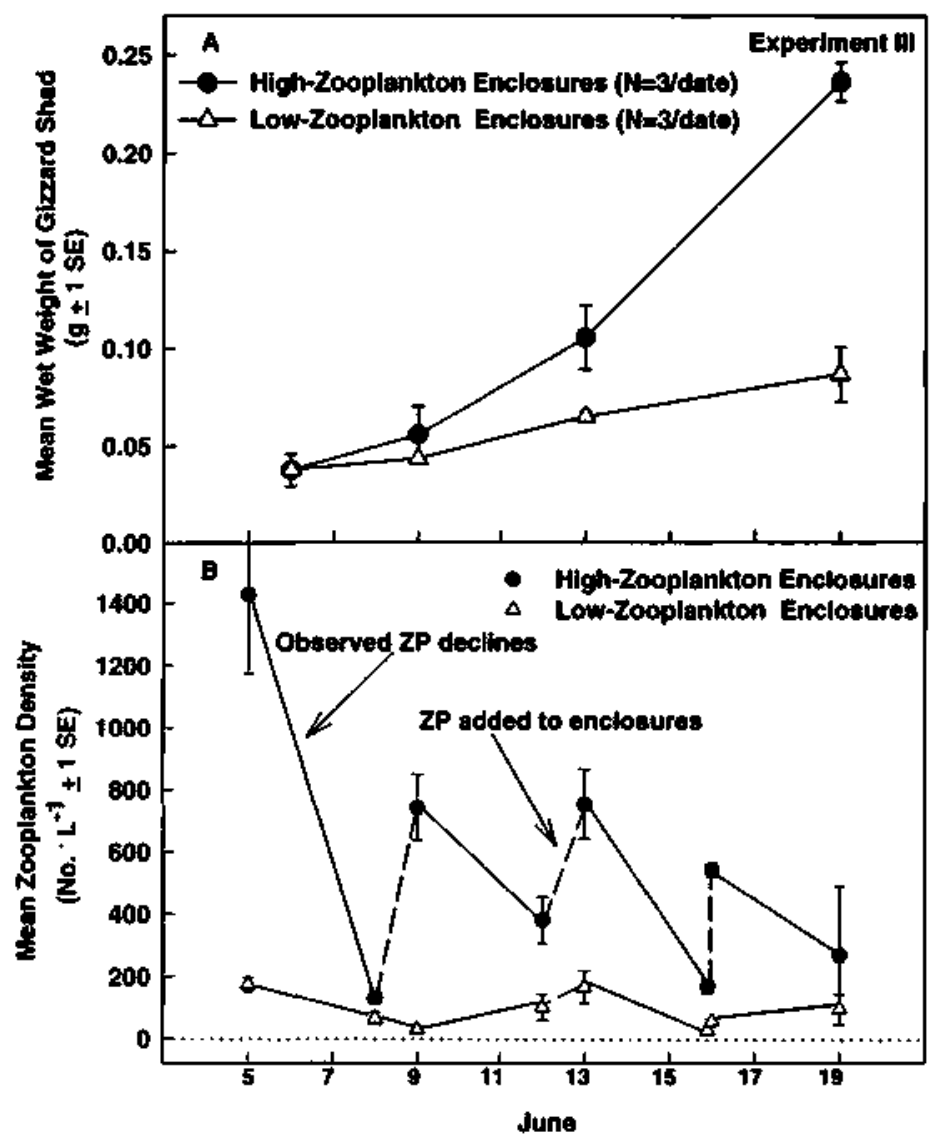

Figure 6.-(A) Mean wet weight of age-0 gizzard shad survivors through time in enclosures with high- and lowzooplankton densities in a pond at the Hebron State Fish Hatchery during experiment 3 (June 6-19, 1995); (B) crustacean zooplankton dynamics (number/L) in enclosures with high or low zooplankton densities. Solid lines designate declines in zooplankton density due, at least in part, to consumption by gizzard shad. Dotted lines represent an increase in zooplankton density due to addition of zooplankton.

Those patterns that link life history characteristics (i.e., small hatch size) to recruitment mechanisms (i.e., starvation) can lend insight into recruitment of unstudied fish species. Yet, patterns generated from an aggregation of data across multiple species do not reflect intraspecific relationships (Chambers and Leggett 1992; Pepin and Miller 1993). Therefore, we seek to compare our results with patterns of larval foraging, growth, and survival documented within other larval fishes. In the absence of predation, experimental results generally reveal positive relationships among food availability, larval growth, and survival (Rosenberg and Haugen 1982; Buckley et al. 1987); yet, similar to our results for gizzard shad, survival of larval American shad Alosa sapidissima (16-18 mm TL) was positively correlated with prey density, but growth was not (Johnson and Dropkin 1995). Experiments that incorporate predation risk demonstrate the complex role of larval size in survival. Conventional wisdom holds that predation risk declines with increasing larval size simply because larvae grow beyond a vulnerable size (Houde 1987). However, vulnerability may peak at an intermediate larval size, through an integration between encounter rate of larvae with predators, which probably increases with larval size, and capture rate of larvae by predators, which probably decreases with larval size (Litvak and Leggett 1992). Finally, relative vulnerability may depend on both the size of individual larvae relative to their cohort as well as the mean size of all larvae within the cohort (Pepin et al. 1992). 
The influence of zooplankton size on age-0 fish success has been experimentally documented in capelin Mallotus villosus, bloater Coregonus hoyi, and yellow perch Perca flavescens. Of these studies, only larval capelin $(<20 \mathrm{~mm} \mathrm{TL})$, the marine species, grew faster and survived better when small zooplankton were abundant (Frank and Leggett 1986). In contrast, the freshwater species, which at least in the case of bloater are quite resistant to starvation (Rice et al. 1987), were studied at larger sizes (bloater, >60 mm TL: Miller et al. 1990; yellow perch, $>30 \mathrm{~mm}$ TL: Mills et al. 1989a). These fishes experienced greater success with large zooplankton. Therefore, differences in zooplankton size distributions across freshwater systems during the period that fish are recruiting could contribute to patterns in fish community composition (Bremigan and Stein 1994). In small-zooplankton systems, gizzard shad recruitment should be favored, whereas in large-zooplankton systems, only large-gaped age-0 fishes, such as bloater and yellow perch, should be favored. Although growth and survival of larvae of largegaped species may not suffer in small-zooplankton systems, their growth as juveniles should be lower than in large-zooplankton systems, thus prolonging their vulnerability to size-dependent predation (Crowder et al. 1987; Luecke et al. 1990; Miller et al. 1990).

\section{Implications for Ohio Reservoirs}

To explore the implications of our experimental results to gizzard shad recruitment in Ohio reservoirs, we must consider all mechanisms likely to influence recruitment. Certainly abiotic factors (particularly temperature), in addition to starvation or predation, can play a key role in dictating fish recruitment. If abiotic conditions are unfavorable, we would expect poor recruitment of gizzard shad, regardless of zooplankton availability. But when abiotic conditions are favorable, we predict that zooplankton availability will strongly affect larval gizzard shad survival. Accordingly, to generate field predictions, we must first compare our experimental zooplankton assemblages to those typical of Ohio reservoirs. The zooplankton density range (0200 zooplankton/L), which elicited the greatest range of larval foraging success, typically occurs across Ohio reservoirs (Bremigan, unpublished data); further, reservoir zooplankton densities rarely exceed 300 zooplankton/L, indicating that starvation could be a dominant source of mortality among small larvae. Zooplankton size in reservoirs is small compared with natural lakes (mean zooplankton size $<0.6 \mathrm{~mm}$ in 11 of 11 reservoirs and $<0.4 \mathrm{~mm}$ in 7 of the 11; Bremigan, unpublished data); yet the mean size range across reservoirs is still broader than our difference in experiment 2. Based on our experimental results, variability in size and density of zooplankton across Ohio reservoirs should influence larval gizzard shad recruitment in terms of both survival to the juvenile stage and growth of juvenile fish.

What then are the implications for sport fish recruitment in Ohio reservoirs? Variability in abundance and growth rates of juvenile gizzard shad can affect sport fish recruitment directly via size-dependent vulnerability of juvenile gizzard shad to age- 0 predators and indirectly via effects of juvenile gizzard shad consumption on zooplankton density available to later-spawned zooplanktivorous larvae (Stein et al. 1995, 1996). Situations that promote rapid growth of age-0 gizzard shad may allow these fish to escape vulnerability to age-0 predators sooner in their life. As such, reservoirs with high levels of zooplankton production throughout the juvenile stage may support relatively rapid growth of juvenile gizzard shad and relatively slow growth of gapelimited age-0 predators. Further, our experimental results indicate that the effects of juvenile gizzard shad consumption on zooplankton density will depend not only on gizzard shad size and abundance, but on their functional response as well. We predict that reservoirs which have high zooplankton densities sufficient to support larval gizzard shad during early spring will be more 
vulnerable to effects of juvenile gizzard shad consumption on zooplankton density.

If variability in size and density of zooplankton available to larval gizzard shad produces variability in juvenile gizzard shad size and abundance, then interactions between larval gizzard shad and their zooplankton prey may predispose reservoirs to specific effects of juvenile gizzard shad. Specifically, we predict that systems with high densities of small zooplankton during the time of larval gizzard shad recruitment will be most vulnerable to subsequent community-wide effects of juvenile gizzard shad. If larval gizzard shad survive well and drive zooplankton to low levels as juveniles, then recruitment of sunfishes Lepomis spp. and largemouth bass Micropterus salmoides may be compromised, thereby structuring the entire fish community (DeVries and Stein 1992; Stein et al. 1995, 1996). Conversely, in reservoirs with low densities of small zooplankton, survival of larval gizzard shad may be quite low, such that community-wide effects of juvenile gizzard shad are nonexistent. Only by understanding ecological processes underlying recruitment of key species (in our case, gizzard shad) can we manage freshwater systems successfully.

\section{Acknowledgments}

We thank Sheri Strong Betz, Laura Circle, Bobbie Jo Kennedy, Gayle Martin, Kathy Massie, and Richelle Neff for their tireless help in the lab and field. Advice regarding experimental design from Libby Marschall and Rusty Wright was much appreciated. Comments on earlier drafts by John Dettmers, Thomas Miller, and Joseph Mion substantially improved the paper. This work was funded by the Department of Zoology at The Ohio State University, Electric Power Research Institute grant 91-07, National Science Foundation grants DEB 9107173 and DEB 9407859, and Federal Aid in Sport Fish Restoration, project F-69-P, administered jointly by the U. S. Fish and Wildlife Service and the Ohio Division of Wildlife. We also thank the Ohio Cooperative Fish and Wildlife Research Unit for contributing facilities and personnel support to this effort.

\section{References}

Blaxter, J. H. S. 1986. Development of sense organs and behavior of teleost larvae with special reference to feeding and predator avoidance. Transactions of the American Fisheries Society 115:98-114.

Bodola, A. 1966. Life history of the gizzard shad, Dorosoma cepedianum (LeSueur), in western Lake Erie. U. S. Fish and Wildlife Service Fishery Bulletin 65:391-425.

Bowen, S. H., E. V. Lutz, and M. O. Ahlgren. 1995. Dietary protein and energy as determinants of food quality: trophic strategies compared. Ecology 76:899-907.

Bremigan, M. T., and R. A. Stein. 1994. Gape-dependent larval foraging and zooplankton size: implications for fish recruitment across systems. Canadian Journal of Fisheries and Aquatic Sciences 51:913-922.

Brooks, J. L., and S. I. Dodson. 1965. Predation, body size, and the composition of plankton. Science 150:28-35.

Buckley, L. J., T. A. Halavik, A. S. Smigielski, and G. C. Laurence. 1987. Growth and survival of the larvae of three species of temperate marine fishes reared at discrete prey densities. Pages 82-92 in R. D. Hoyt, editor. 10th annual larval fish conference. American Fisheries Society Symposium 2, Bethesda, Maryland.

Carlander, K. D. 1969. Handbook of freshwater fishery biology, volume 1. Iowa State University Press, Ames.

Chambers, R. C. 1993. Phenotypic variability in fish populations and its representation in individual-based models. Transactions of the American Fisheries Society 122:404-414.

Chambers, R. C., and W. C. Leggett. 1992. Possible causes and consequences of variation in age and size at metamorphosis in flatfishes (Pleuronectiformes): an analysis at the individual, population, and species level. Netherlands Journal of Sea Research 29:7-24.

Chesson, J. 1978. Measuring preference in selective predation. Ecology 59:211-215.

Chesson, J. 1983. The estimation and analysis of preference and its relationship to foraging models. Ecology 64:1297-1304.

Crowder, L. B., M. E. McDonald, and J. A. Rice. 1987. Understanding recruitment mechanisms of Lake Michigan 
fishes: the importance of size-based interactions between fish and zooplankton. Canadian Journal of Fisheries and Aquatic Sciences 44(Supplement 2):141-147.

Cushing, D. H. 1990. Plankton production and year-class strength in fish populations: an update of the match/mismatch hypothesis. Advances in Marine Biology 26:249-293.

Dettmers, J. M., and R. A. Stein. 1992. Food consumption by larval gizzard shad: zooplankton effects and its implications for reservoir communities. Transactions of the American Fisheries Society 121:494-507.

Dettmers, J. M., and R. A. Stein. 1996. Quantifying linkages among gizzard shad, zooplankton, and phytoplankton in reservoirs. Transactions of the American Fisheries Society 125:27-41.

DeVries, D. R., and R. A. Stein. 1990. Manipulating shad to enhance sport fisheries in North America: an assessment. North American Journal of Fisheries Management 10:209-223.

DeVries, D. R., and R. A. Stein. 1992. Complex interactions between fish and zooplankton: quantifying the role of an open-water planktivore. Canadian Journal of Fisheries and Aquatic Sciences 49:1216-1227.

Forney, J. L. 1976. Year-class formation in the walleye (Stizostedion vitreum vitreum) population of Oneida Lake, New York, 1966-1973. Journal of the Fisheries Research Board of Canada 33:783-792.

Frank. K. T., and W. C. Leggett. 1986. Effect of prey abundance and size on the growth and survival of larval fish: an experimental study employing large volume enclosures. Marine Ecology Progress Series 34:11-22.

Houde, E. D. 1987. Fish early life dynamics and recruitment variability. Pages 17-29 in R. D. Hoyt, editor 10th annual larval fish conference. American Fisheries Society Symposium 2. Bethesda, Maryland.

Houde, E. D. 1994. Differences between marine and freshwater fish larvae: implications for recruitment. ICES Journal of Marine Science 51:91-97.

Hunter, J. R. 1981. Feeding ecology and predation of marine fish larvae. Pages 34-77 in R. Lasker, editor. Marine fish larvae: morphology, ecology, and relation to fisheries. University of Washington Press, Seattle.

Johnson, J. H., and D. S. Dropkin. 1995. Effects of prey density and short term food deprivation on the growth and survival of American shad larvae. Journal of Fish Biology 46:872-879.

Jude, D, J. 1973. Food and feeding habits of gizzard shad in pool 19, Mississippi River. Transactions of the American Fisheries Society 102:378-383.

Kissick, L. A. 1988. Early life history of the gizzard shad in Acton Lake, Ohio: feeding ecology and drift of stream spawned larvae. Master's thesis. Miami University, Oxford, Ohio.

Leggett, W. C., and E. DeBlois. 1994. Recruitment in marine fishes: is it regulated by starvation and predation in the egg and larval stages? Netherlands Journal of Sea Research 32:119-134.

Litvak, M. K., and W. C. Leggett. 1992. Age and size-selective predation on larval fishes: the bigger is better paradigm revisited. Marine Ecology Progress Series 81:13-24.

Luecke, C., J. A. Rice, L. B. Crowder, S. E. Yeo, and F. P. Binkowski. 1990. Recruitment mechanisms of bloater in Lake Michigan: an analysis of the predatory gauntlet. Canadian Journal of Fisheries and Aquatic Sciences 47:524-532.

Mathias. J. A., and S. Li. 1982. Feeding habits of walleye larvae and juveniles: comparative laboratory and field studies. Transactions of the American Fisheries Society 111:722-735.

Miller, T. J., L. B. Crowder, and F. P. Binkowski. 1990. Effects of changes in the zooplankton assemblage on growth of bloater and implications for recruitment success. Transactions of the American Fisheries Society 119:483-491.

Miller, T. J., L. B. Crowder, J. A. Rice, and E. A. Marschall. 1988. Larval size and recruitment mechanisms in fishes: toward a conceptual framework. Canadian Journal of Fisheries and Aquatic Sciences 45:1657-1670.

Mills, E. L., and J. L. Forney. 1988. Trophic dynamics and development of freshwater pelagic food webs. Pages 1130 in S. R. Carpenter, editor. Complex interactions in lake communities. Springer-Verlag, New York.

Mills, E. L., D. M. Green, and A. Schiavone, Jr. 1987. Use of zooplankton size to assess the community structure of fish populations in freshwater lakes. North American Journal of Fisheries Management 7:369-378.

Mills, E. L., M. V. Pol, R. E. Sherman, and T. B. Culver. 1989b. Interrelationships between prey body size and growth of age- 0 yellow perch. Transactions of the American Fisheries Society 118:1-10.

Mills, E. L., R. Sherman, and D. S. Robson. 1989a. Effect of zooplankton abundance and body size on growth of age-0 yellow perch (Perca flavescens) in Oneida Lake, New York, 1975-1986. Canadian Journal of Fisheries and Aquatic Sciences 46:880-886.

Pedersen, B. H., I. Ugelstad, and K. Hjelmeland. 1990. Effects of a transitory, low food supply in the early life of larval herring (Clupea harengus) on mortality, growth, and digestive capacity. Marine Biology 107:61-66.

Pepin, P., and T. J. Miller. 1993. Potential use and abuse of general empirical models of early life history processes in fish. Canadian Journal of Fisheries and Aquatic Sciences 50:1343-1345.

Pepin, P., T. H. Shears, and Y. deLafontaine. 1992. Significance of body size to the interaction between a larval fish 
(Mallotus villosus) and a vertebrate predator (Gasterosteus aculeatus). Marine Ecology Progress Series 81:1-12.

Rice, J. A., L. B. Crowder, and M. E. Holey. 1987. Exploration of mechanisms regulating larval survival in Lake Michigan bloater: recruitment analysis based on characteristics of individual larvae. Transactions of the American Fisheries Society 116:703-718.

Rosenberg, A. A., and A. S. Haugen. 1982. Individual growth and size-selective mortality of larval turbot (Scophthalmus maximus) reared in enclosures. Marine Biology 72:73-77.

SAS Institute. 1985. SAS user's guide: statistics, version 5 edition. SAS Institute, Cary, North Carolina.

Schael, D. M., L. G. Rudstam, and J. R. Post. 1991. Gape limitation and prey selection in larval yellow perch (Perca flavescens), freshwater drum (Aplodinotus grunniens), and black crappie (Pomoxis nigromaculatus). Canadian Journal of Fisheries and Aquatic Sciences 48:1919-1925.

Siefert, R. E. 1972. First food of larval yellow perch, white sucker, bluegill, emerald shiner, and rainbow smelt. Transactions of the American Fisheries Society 101:219-225.

Stein, R. A., M. T. Bremigan, and J. M. Dettmers. 1996. Understanding reservoir systems with experimental tests of ecological theory: a prescription for management. Pages 12-27 in L. E. Miranda and D. R. DeVries, editors. Multidimensional approaches to reservoir fisheries management. American Fisheries Society, Symposium 16, Bethesda, Maryland.

Stein. R. A., D. R. DeVries, and J. M. Dettmers. 1995. Food-web regulation by a planktivore: exploring the generality of the trophic cascade hypothesis. Canadian Journal of Fisheries and Aquatic Sciences 52:25182526.

von Ende, C. N. 1993. Repeated-measures analysis: growth and other time-dependent measures. Pages 113-137 in S. M. Scheiner and J. Gurevitch, editors. Design and analysis of ecological experiments. Chapman and Hall, New York.

Wong. B., and F. J. Ward. 1972. Size selection of Daphnia pulicaria by yellow perch (Perca flavescens) fry in West Blue Lake, Manitoba. Journal of the Fisheries Research Board of Canada 29:1761-1764.

Yako, L. A., J. M. Dettmers, and R. A. Stein. 1996. Feeding preferences of omnivorous gizzard shad as influenced by fish size and zooplankton density. Transactions of the American Fisheries Society 125:753-759. 